Supporting Information to

\title{
Molecular Filtration by Ultrathin and Highly Porous \\ Silica Nanochannel Membranes - Permeability and \\ Selectivity
}

Qian Yang, Xingyu Lin, Bin Su

Institute of Analytical Chemistry, Department of Chemistry, Zhejiang University, Hangzhou 310058, China

*E-mail: subin@zju.edu.cn

\section{Table of Content}

S1. Chemicals and Materials

S2. Synthesis and Characterization of SNM

S3. Permeation of $\mathrm{MV}^{2+}$ and $\mathrm{FL}^{2-}$ through SNM by Fick Diffusion

S4. Charge Effect on Single-component Permeation

S5. Two-component Permeation of $\mathrm{MV}^{2+}$ and $\mathrm{FL}^{2-}$

S6. Transport of $\mathrm{MV}^{2+}$ and $\mathrm{NDS}^{2-}$ at Different $\mathrm{pH}$ and Ionic Strength

S7. Electric Field Controlled Ion Transport through SNM

S8. Molecule Permeation through Commercial Membranes 


\section{Chemicals and Materials}

Concentrated ammonia aqueous solution $(25 \mathrm{wt} \%)$, tetraethoxysilane (TEOS),

cetyltrimethylammonium bromide (CTAB), poly(methyl methacrylate) (PMMA, $M_{\mathrm{w}}=$ 996000), were all purchased from Sigma.<smiles>O=C([O-])c1ccccc1-c1c2ccc(=O)cc-2oc2cc(Cl)ccc12</smiles>

fluorescein $\left(\mathrm{FL}^{2-}\right)$

$(1.1 \mathrm{~nm})$

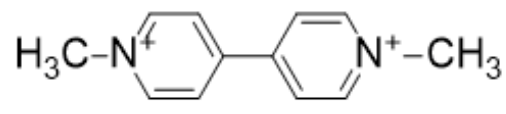

methyl viologen $\left(\mathrm{MV}^{2+}\right)$

$(0.53 \mathrm{~nm})$<smiles>O=S(=O)([O-])c1cccc2c(S(=O)(=O)O)cccc12</smiles>

1.5-naphthalene disulfonate (NDS $\left.{ }^{2-}\right)$

$(0.55 \mathrm{~nm})$

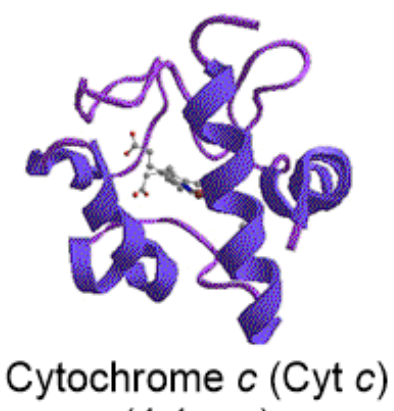

$(4.1 \mathrm{~nm})$

Figure S1. The molecular probes used in this work. 


\section{S2. Synthesis and Characterization of SNM}

The SNM was grown on the ITO glass by the Stöber-solution growth approach. ${ }^{1}$ Briefly, the ITO glass was firstly immersed in $1 \mathrm{M} \mathrm{NaOH}$ ethanol solution overnight, and cleaned under ultrasonication in acetone, ethanol and water sequentially, each for $15 \mathrm{~min}$. Subsequently, the ITO glass was immersed in the mixture containing $70 \mathrm{~mL}$ water, 30 $\mathrm{mL}$ ethanol, $10 \mu \mathrm{L}$ ammonia aqueous solution, $0.16 \mathrm{~g}$ cetyltrimethylammonium bromide (CTAB) and $80 \mu \mathrm{L}$ tetraethoxysilane (TEOS). Then, the SNM gradually grew on the ITO glass surface under quiescent condition at $60^{\circ} \mathrm{C}$. After $24 \mathrm{~h}$, the ITO glass with SNM on it (designated as SNM/ITO) was rinsed with water and then dried and aged at $100{ }^{\circ} \mathrm{C}$ overnight. CTAB surfactants existed in the form of micelles in the silica nanochannels were removed by immersing the SNM/ITO in $0.1 \mathrm{M} \mathrm{HCl}$ ethanol solution under moderate stirring for $10 \mathrm{~min}$.


Figure S2. (a) SEM image of SNM grown on ITO glass surface. (b, c) Top-view (b) and cross-section view (c) of TEM images of SNM scraped from the ITO glass surface.

The structure and morphology of as prepared SNM was characterized by SEM and TEM measurements. As shown in Figure S2a, three layers can be clearly identified from top to bottom, corresponding to the SNM, ITO and glass substrate. The thickness of 
SNM is ca. $94 \mathrm{~nm}$. From the top-view of TEM image (Figure S2b), one can see a large number of mesopores, which appears as bright spots and regularly distributes over a large area without cracks. The pore diameter is ca. $2.3 \mathrm{~nm}$ and the pore density is up to $4.0 \times 10^{12}$ pores $\mathrm{cm}^{-2}$, corresponding to pore density of $16.7 \%$. Figure S2c displays the cross-section of view of SNM, from which the vertically aligned and parallel silica nanochannels can be recognized.

The SNM/p-SiN was prepared according to our previously work. ${ }^{2}$ Briefly, PMMA solution (3.5 wt \%) was spin-coated on the top of SNM/ITO, which was immersed into $2 \mathrm{M} \mathrm{HCl}$ aqueous solution at room temperature to etch the ITO layer. Then SNM was cleaned for three times by immersing in water using PET as a transfer substrate. Thus obtained PMMA/SNM was then fished out by the p-SiN chip and dried naturally. Finally, $\mathrm{SNM} / \mathrm{p}-\mathrm{SiN}$ with perforated channels, in a form of nanochannels-on-micropores, was obtained after immersed in acetone to dissolve the top PMMA layer. 


\section{S3. Permeation of $\mathrm{MV}^{2+}$ and $\mathrm{FL}^{2-}$ through SNM by Fick Diffusion}

Molecular transport through the nanoporous membrane can proceed via Fick diffusion or single file diffusion. Typically, the latter case will prevail when the diameter of molecule is larger than the radius of channel. And the permeation flux is independent on the initial concentration of molecules in the feed solution. To examine whether Fick or single file diffusion occurs for the molecular permeation at the SNM, we investigated the permeation of $\mathrm{MV}^{2+}$ and $\mathrm{FL}^{2-}$ at two different initial concentrations. As shown in Figure S3, when increasing the concentration from $5 \mathrm{mM}$ to $9.1 \mathrm{mM}$, the permeation fluxes were increased from $4.69 \mu \mathrm{mol} \mathrm{m^{-1 }} \mathrm{cm}^{-2}$ to $8.73 \mu \mathrm{mol} \mathrm{min}{ }^{-1} \mathrm{~cm}^{-2}$ for $\mathrm{MV}^{2+}$ and


the permeation of these two molecules through SNM took place via Fick diffusion instead of single file diffusion.
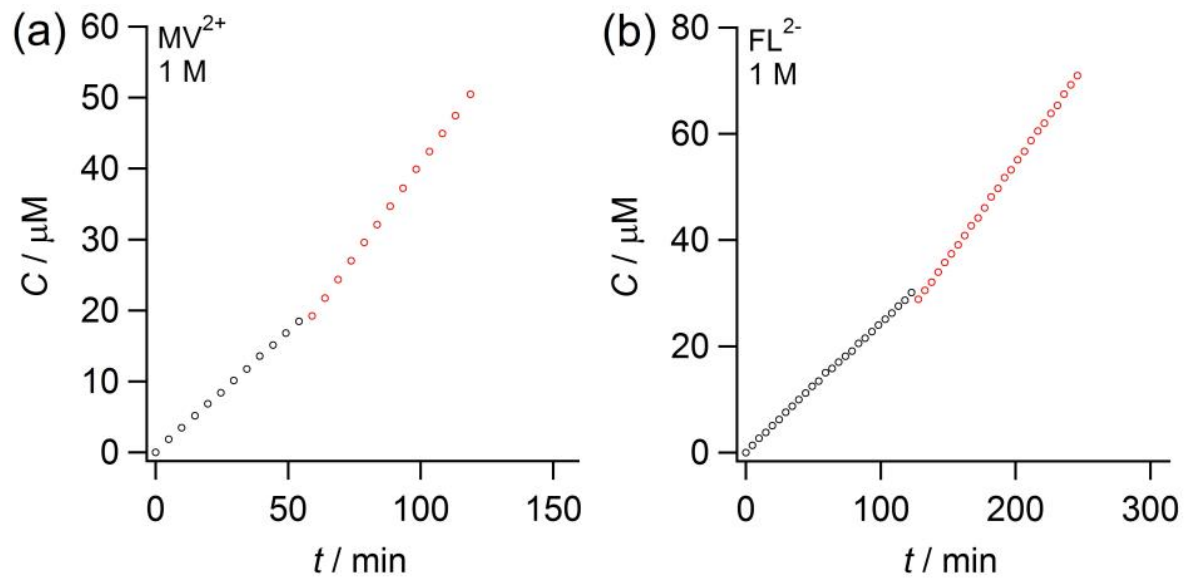

Figure S3. Kinetic permeation plots of $\mathrm{MV}^{2+}$ (a) and $\mathrm{FL}^{2-}$ (b) before (black circles) and after (red circles) increasing the probe concentration. The initial concentration of probes in the feed cell was $5 \mathrm{mM}$. $100 \mu \mathrm{L}$ stock solution containing $50 \mathrm{mM}$ probes was added to increase the concentration. In both feed and stock solutions, $1 \mathrm{M} \mathrm{KCl}$ was dissolved to maintain a constant ionic strength. 


\section{S4. Charge Effect on Single-component Permeation}

Molecule permeation experiments were conducted using $5 \mathrm{mM} \mathrm{NDS}^{2-}, \mathrm{MV}^{2+}$, or $\mathrm{FL}^{2-}$ as probes in the feed solution. The concentration of electrolyte in both feed and permeate solutions was the same, and varied from $1 \mathrm{mM}$ to $1 \mathrm{M}$ to regulate the magnitude of the Debye length. The UV spectra were recorded in the course of permeation, as shown in Figure S4, Figure S5, and Figure S6.

In the case of anionic NDS ${ }^{2-}$ and $\mathrm{FL}^{2-}$ (Figures S4 and S6), the UV absorbance increased more rapidly at a high electrolyte concentration. This can be ascribed to the screening effect of electrolyte ions, which attenuated the electrostatic repulsion from the channel surface.

In the case of cationic $\mathrm{MV}^{2+}$ (Figures S5), the situation was reversed. Due to a stronger electrostatic attraction is expected at a low electrolyte concentration, the permeation of $\mathrm{MV}^{2+}$ is faster in this case.
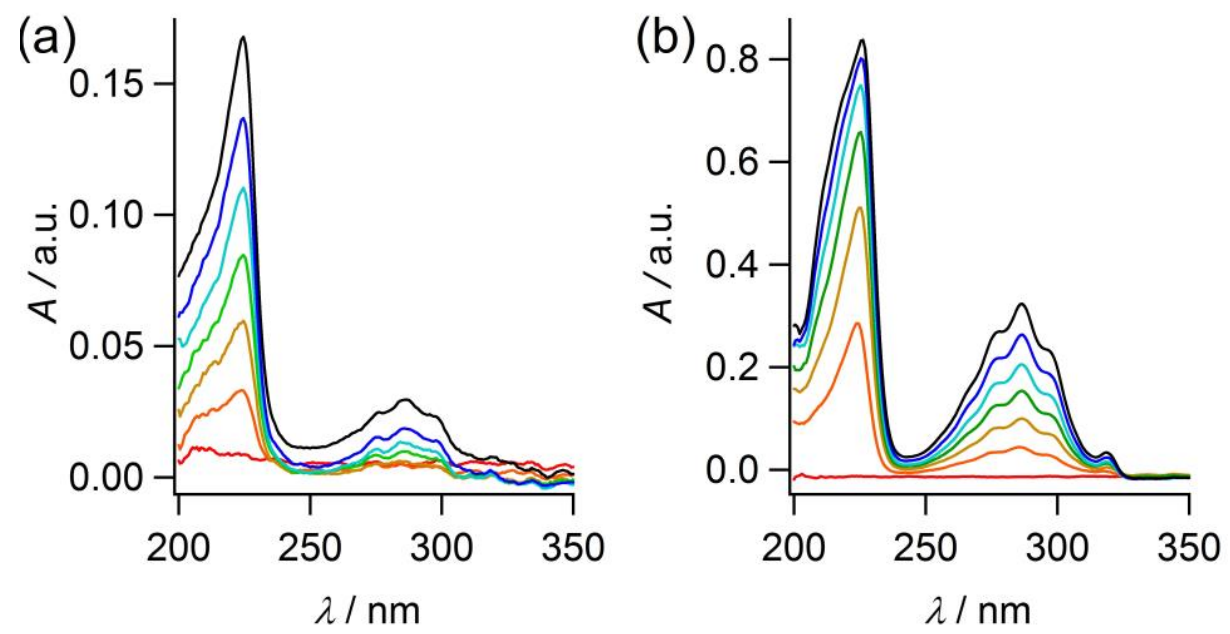

Figure S4. The UV-vis spectra of $\mathrm{NDS}^{2-}$ in the permeate solution recorded every 30 $\mathrm{min}$ in the course of permeation experiment. The salt concentration was $1 \mathrm{mM} \mathrm{KCl}$ (a) and $1 \mathrm{M} \mathrm{KCl}(\mathrm{b})$. 



Figure S5. The UV-vis spectra of $\mathrm{MV}^{2+}$ in the permeate solution recorded at $30 \mathrm{~min}, 60$ min, $120 \mathrm{~min}$ and $180 \mathrm{~min}$ in the course of permeation experiment. The salt concentration was $1 \mathrm{mM} \mathrm{KCl} \mathrm{(a)} \mathrm{and} 1 \mathrm{M} \mathrm{KCl} \mathrm{(b).}$
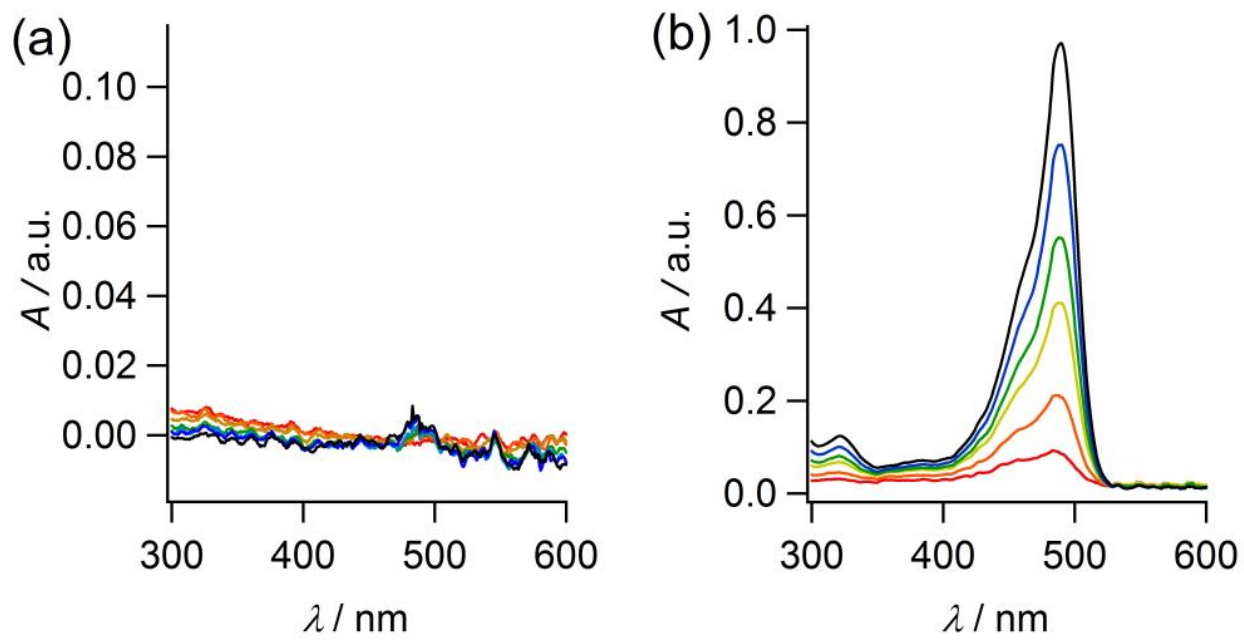

Figure S6. The UV-vis spectra of $\mathrm{FL}^{2-}$ in the permeate solution recorded every $30 \mathrm{~min}$ in the course of permeation experiment. The salt concentration was $1 \mathrm{mM} \mathrm{KCl}$ (a) and 1 $\mathrm{M} \mathrm{KCl} \mathrm{(b).}$ 


\section{S5. Two-component Permeation of $\mathrm{MV}^{2+}$ and $\mathrm{FL}^{2-}$}

Two-component permeation experiments were investigated by mixing $2.5 \mathrm{mM} \mathrm{MV}^{2+}$ and $2.5 \mathrm{mM} \mathrm{FL}^{2-}(1 \mathrm{mM} \mathrm{KCl})$ in the feed cell so that the total ionic strength was the same as in the single-component permeation. The absorption spectra for each $\mathrm{MV}^{2+}, \mathrm{FL}^{2-}$, and mixture of $\mathrm{MV}^{2+}-\mathrm{FL}^{2-}$ pair are shown in Figure S7a. $\mathrm{MV}^{2+}$ shows a strong band centered at $257 \mathrm{~nm}$, where $\mathrm{FL}^{2-}$ absorbance is weak. $\mathrm{FL}^{2-}$ shows a characteristic sharp band centered at $490 \mathrm{~nm}$, where $\mathrm{MV}^{2+}$ absorbance can barely be observed. The absorption spectra of the permeate solution were recorded every $30 \mathrm{~min}$ after the experiment began, as shown in Figure S7b.

Due to the 16-fold increased flux of $\mathrm{FL}^{2-}$ and twice decreased flux of $\mathrm{MV}^{2+}$ was observed in two-component experiments, the titration experiment in situ was performed as $100 \mu \mathrm{L} 50 \mathrm{mM} \mathrm{MV}^{2+}\left(\mathrm{FL}^{2-}\right)$ was added into feed solution of $5 \mathrm{mM} \mathrm{FL}^{2-}\left(\mathrm{MV}^{2+}\right)$ after $3 \mathrm{~h}(1 \mathrm{~h})$ and $100 \mu \mathrm{L} 1 \mathrm{mM} \mathrm{KCl}$ was added into permeation solution at the same time. The results were that, shown in Figure S8, the flux of $\mathrm{FL}^{2-}$ increased 14-fold after adding $\mathrm{MV}^{2+}$, while it decreased twice for $\mathrm{MV}^{2+}$ when adding $\mathrm{FL}^{2-}$, which indicated that the phenomenon was not caused by difference between SNMs as well.
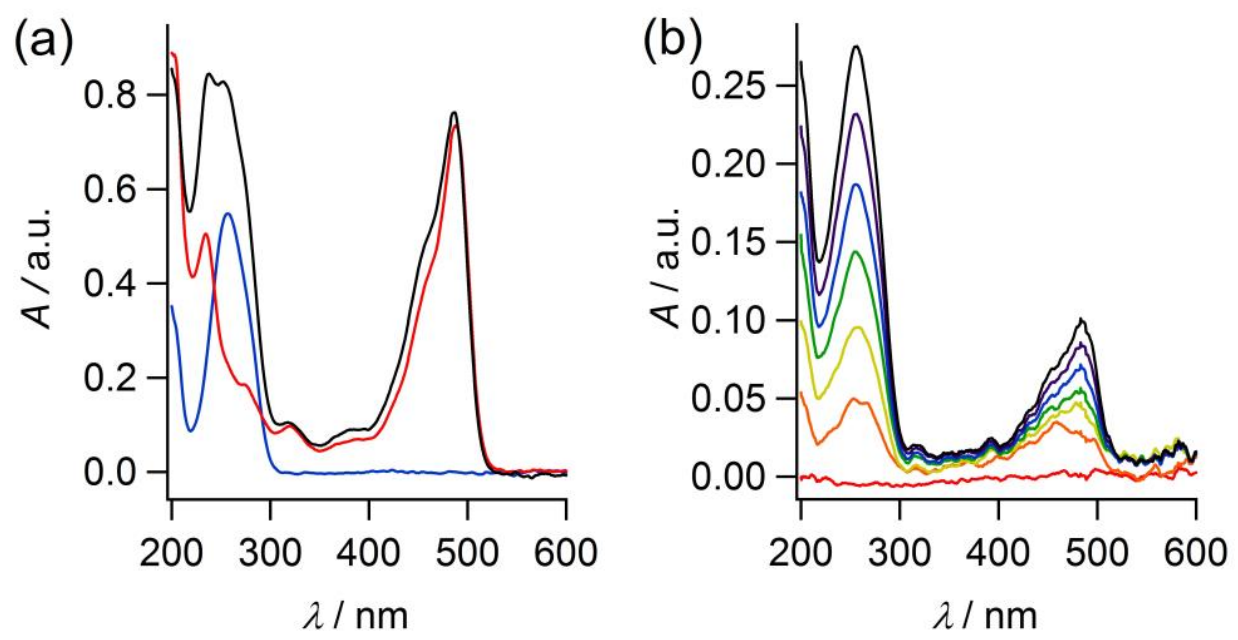

Figure S7. (a) Absorption spectra of $30 \mu \mathrm{M} \mathrm{MV}{ }^{2+}$ (blue), $30 \mu \mathrm{M} \mathrm{FL}^{2-}$ (red) and their mixture (black). (b) The UV-vis spectra for two-component permeation of $\mathrm{MV}^{2+} / \mathrm{FL}^{2-}$ (2.5 $\mathrm{mM} / 2.5 \mathrm{mM}$ ) in the permeate solution recorded every $30 \mathrm{~min}$. The salt concentration was $1 \mathrm{mM} \mathrm{KCl}$. 


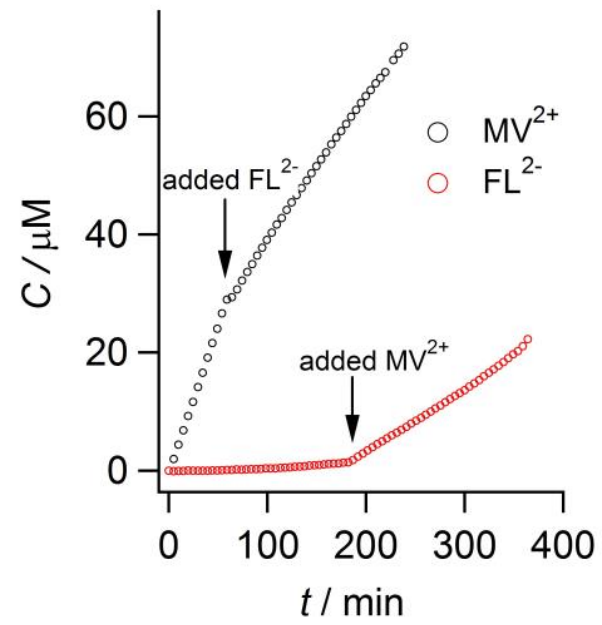

Figure S8. Kinetic plots for the single-component permeation of $\mathrm{MV}^{2+}$ (black circles) and $\mathrm{FL}^{2-}$ (red circles). The initial concentration of $\mathrm{FL}^{2-}$ or $\mathrm{MV}^{2+}$ was $5 \mathrm{mM}$ and $1 \mathrm{mM}$ $\mathrm{KCl}$ was used as the electrolyte. $100 \mu \mathrm{L}$ of $50 \mathrm{mM} \mathrm{FL}^{2-}$ or $50 \mathrm{mM} \mathrm{MV}^{2+}$ was added to the feed solution after $1 \mathrm{~h}$ (black circles) or after $3 \mathrm{~h}$ (red circles). 


\section{S6. Transport of $\mathrm{MV}^{2+}$ and $\mathrm{NDS}^{2-}$ at Different $\mathrm{pH}$ and Ionic Strength}

Not only the ionic strength but also the $\mathrm{pH}$ would regulate the charge on nanochannels to vary the transport dynamic behavior for ions across nanochannels. Instead of $\mathrm{KCl}$, use $1 \mathrm{mM} \mathrm{HCl}(\mathrm{pH} 3.0)$ as electrolyte, the dynamic plots of $\mathrm{NDS}^{2-}\left(\mathrm{MV}^{2+}\right)$ was seen in Figure S9, comparing with that using $\mathrm{KCl}$, showing the flux of $\mathrm{MV}^{2+}$ was slower than that of $\mathrm{NDS}^{2-}$ at $\mathrm{pH} 3.0$.
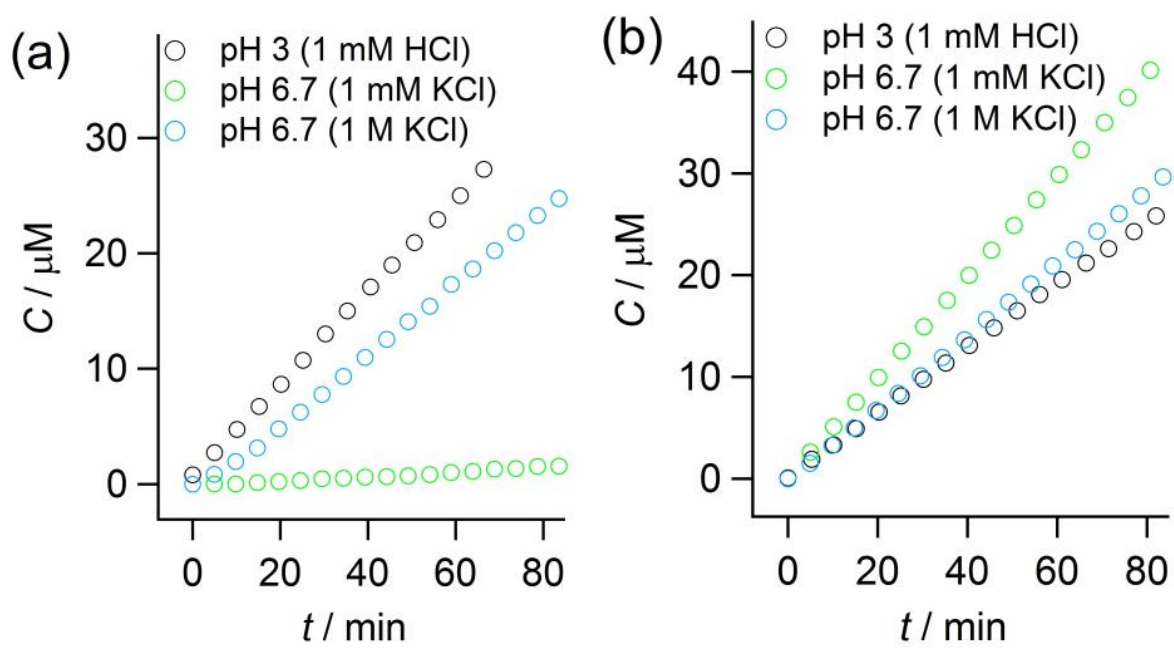

Figure S9. Kinetic plots for the single-component permeation of $\mathrm{NDS}^{2-}$ (a) and $\mathrm{MV}^{2+}$ (b) at pH 3.0 (black circles, $1 \mathrm{mM} \mathrm{HCl}$ ) and pH 6.7 (green circles, $1 \mathrm{mM} \mathrm{KCl}$; blue circles, $1 \mathrm{M} \mathrm{KCl})$. 


\section{S7. Electric Field Controlled Ion Transport through SNM}
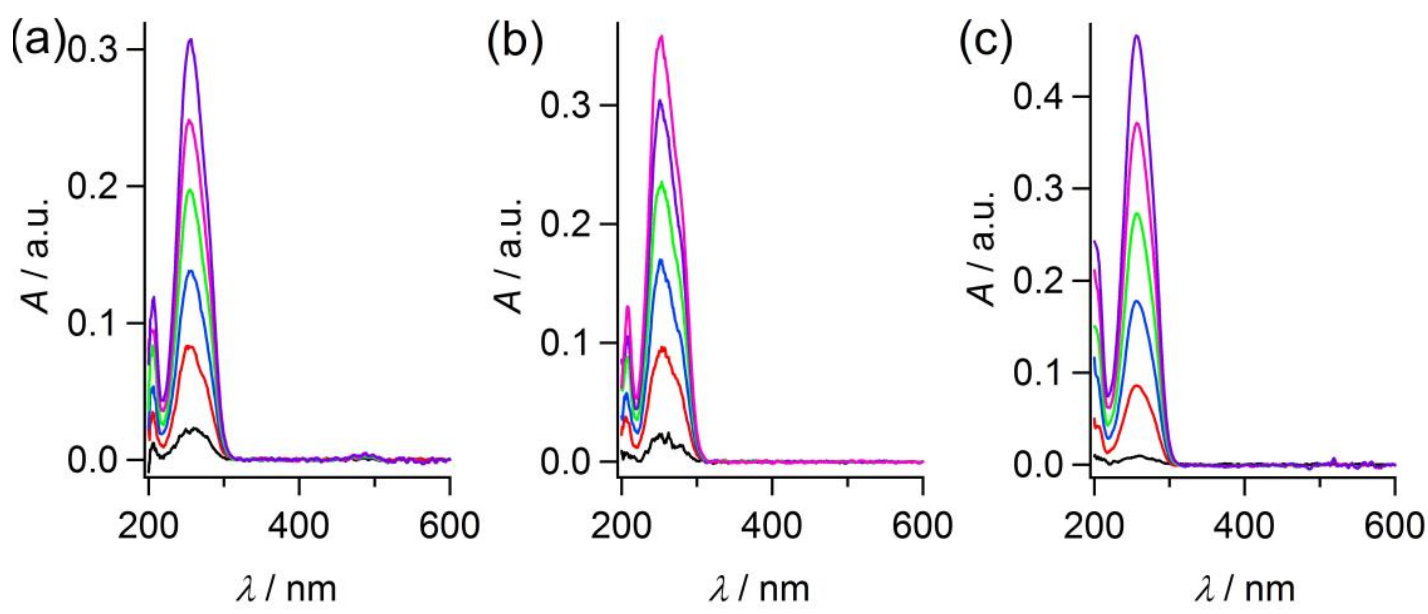

Figure S10. The UV-visible spectra for two-component permeation of $\mathrm{MV}^{2+} / \mathrm{FL}^{2-}(2.5$ $\mathrm{mM} / 2.5 \mathrm{mM}$ ) recorded every $5 \mathrm{~min}$ upon applying different positive voltage (feed versus permeate): $+0.5 \mathrm{~V}(\mathrm{a}),+0.8 \mathrm{~V}$ (b) and $+1.0 \mathrm{~V}(\mathrm{c})$
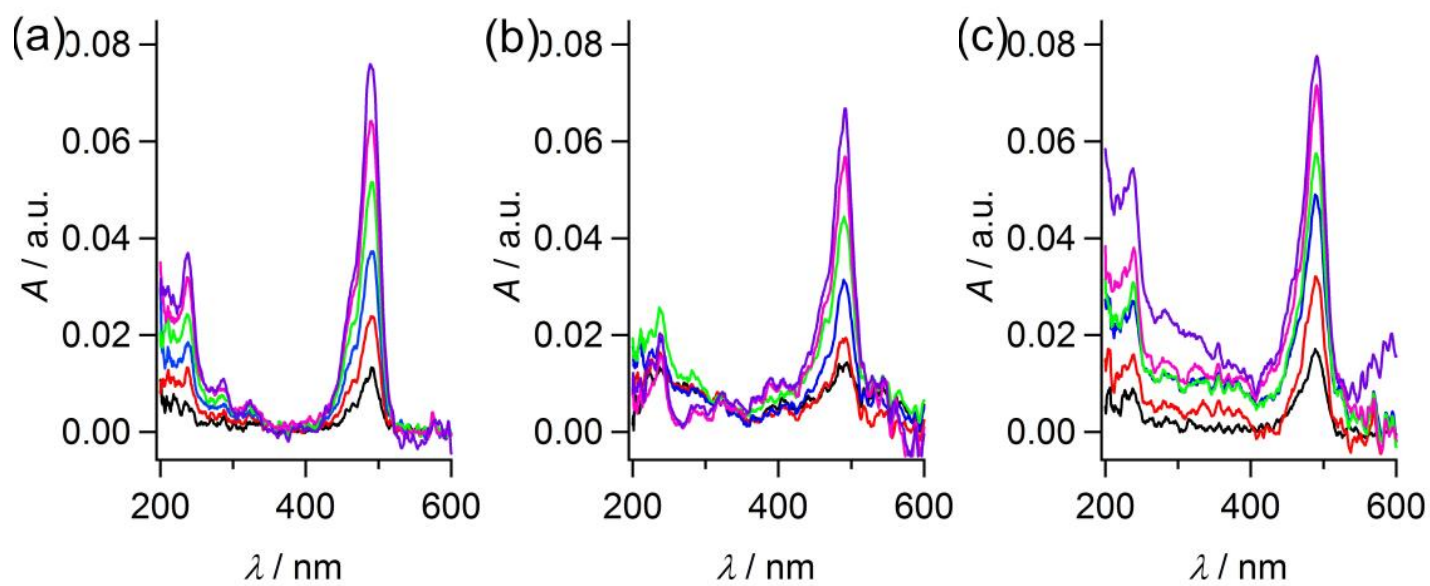

Figure S11. The UV-visible spectra for two-component permeation of $\mathrm{MV}^{2+} / \mathrm{FL}^{2-}(2.5$ $\mathrm{mM} / 2.5 \mathrm{mM}$ ) recorded every $5 \mathrm{~min}$ upon applying different negative voltage (permeate versus feed): $-0.5 \mathrm{~V}(\mathrm{a}),-0.8 \mathrm{~V}$ (b) and $-1.0 \mathrm{~V}$ (c). 


\section{S8. Molecule Permeation through Commercial Membranes}

Compare the molecular flux at the SNM with the commercial dialysis membrane experimentally. It was conducted by $1 \mathrm{M} \mathrm{KCl}$ to ignore the effect of EDL. Figure S12a shows the UV spectra of permeation of $\mathrm{FL}^{2-}$ across the dialysis membrane, which was increased to 1.4 at $490 \mathrm{~nm}$ after $60 \mathrm{~min}$. However, the normalized flux of dialysis membrane was ca. 830 -fold (3.0810 versus $0.0037 \mu \mathrm{mol} \mathrm{cm}^{-2} \mathrm{~min}^{-1}$ ) smaller than that of SNM, as shown in Figure S12b.
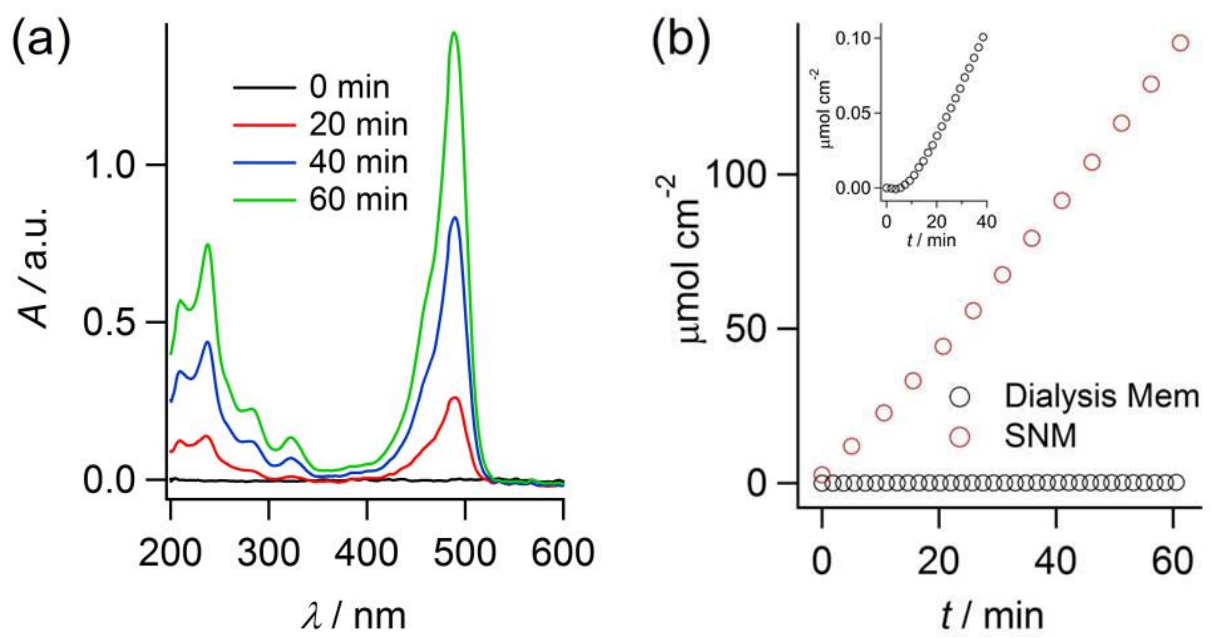

Figure S12. (a) The UV-visible spectra for single-component permeation of $\mathrm{FL}^{2-}(5 \mathrm{mM})$ across the dialysis membrane $(6 \mathrm{kD}-8 \mathrm{kD})$ for different times. (b) The permeation kinetic plots normalized by the membrane area for dialysis membrane (black circles) and SNM (red circles). The effective area of dialysis membrane used in our system was 0.28 $\mathrm{cm}^{2}$. The inset is the amplified view of $\mathrm{FL}^{2-}$ permeation across the dialysis membrane at short times.

\section{References}

(1) Teng, Z.; Zheng, G.; Dou, Y.; Li, W.; Mou, C.-Y.; Zhang, X.; Asiri, A. M.; Zhao, D. Angew. Chem. Int. Ed. 2012, 51, 2173-2177.

(2) Lin, X.; Yang, Q.; Ding, L.; Su, B. ACS Nano 2015, 9, 11266-11277. 